\title{
Irradiation Damage and Semiconducting Properties of $\backslash\left(\mathrm{CdF} \_2: \mathrm{Eu}\right)$
}

\section{Citation}

Tzalmona, A. and Peter S. Pershan. 1971. Irradiation damage and semiconducting properties of V(CdF_2:Eu). Journal of Chemical Physics 55(10): 4804-4811.

\section{Published Version}

doi:10.1063/1.1675582

\section{Permanent link}

http://nrs.harvard.edu/urn-3:HUL.InstRepos:10361958

\section{Terms of Use}

This article was downloaded from Harvard University's DASH repository, and is made available under the terms and conditions applicable to Other Posted Material, as set forth at http:// nrs.harvard.edu/urn-3:HUL.InstRepos:dash.current.terms-of-use\#LAA

\section{Share Your Story}

The Harvard community has made this article openly available.

Please share how this access benefits you. Submit a story.

\section{Accessibility}




\title{
Irradiation Damage and Semiconducting Properties of $\mathrm{CdF}_{2}: \mathrm{Eu}^{*}$
}

\author{
A. Tzalmonat and P. S. Pershan \\ Division of Engineering and Applied Physics, Harvard University, Cambridge, Massachusetts 02138
}

(Received 11 June 1971)

\begin{abstract}
Thermoluminescence data have been used to unravel the fluorescence spectrum of $\mathrm{Eu}^{3+}$ in the insulating $\mathrm{CdF}_{2}$ host. Optical absorption and EPR measurements of semiconducting $\mathrm{CdF}_{2}: \mathrm{Eu}$ are the bases of a model of this semiconductor.
\end{abstract}

\section{INTRODUCTION}

Cadmium fluorite has the well-known fluorite structure. The series of $\mathrm{MeF}_{2}$ crystals $(\mathrm{Me}=\mathrm{Cd}, \mathrm{Ca}$, $\mathrm{Sr}, \mathrm{Ba}$ ) are easily doped with rare earths. The rareearth impurity, usually in the trivalent state, substitutes for the divalent cation. The charge compensation needed is usually provided by an interstitial $\mathrm{F}^{-}$ atom. Kingsley and Prener $^{1}$ discovered that baking the $\mathrm{CdF}_{2}$ doped with some rare earths in $\mathrm{Cd}$ vapor results in transforming the colorless and insulating crystal into a colored semiconductor. During the process of baking of $\mathrm{MeF}_{2}$ in the metal vapor, interstitial fluorine atoms are believed to diffuse to the surface, forming $\mathrm{MeF}_{2}$ with the metal vapor, and for each one molecule two electrons are liberated into the lattice. In the case of $\mathrm{Me}=\mathrm{Ca}, \mathrm{Sr}, \mathrm{Ba}^{2}$ the rare earth is converted to the divalent state. In $\mathrm{CdF}_{2}$, however, even at low temperatures, ${ }^{3}$ there is no evidence of most of the rare earth in the divalent state. The difference can most probably be attributed to the greater electron affinity of the $\mathrm{Cd}^{2+}$ compared to $\mathrm{Ca}^{2+}, \mathrm{Sr}^{2+}$, and $\mathrm{Ba}^{2+} .{ }^{4}$ The electrons are located at cadmium sites and form a conduction band. It has been shown by EPR and optical studies that ${ }^{5}$ some of the rare earths represent a "shallow trap" for the conducting electron in the sense that the electron is free to move around the trivalent rare earth on the cadmium sites without converting it to the divalent state.

In $\mathrm{CdF}_{2}: \mathrm{Eu}$, however, it has been shown ${ }^{6}$ that the converted crystals exhibit $\mathrm{Eu}^{2+}$ optical properties. The resistivity of the converted sample is of the order of a few hundred ohm - centimeters compared to a few ohm-centimeters for the shallow traps such as Nd, Sm, Tb, Dy, Ho, Tm. Resistivity measurements show the energy gap of the europium-doped semiconducting $\mathrm{CdF}_{2}$ is $0.33 \mathrm{eV}$. $^{6}$

The purpose of the present work is to confirm that $\mathrm{Eu}^{3+}$ in $\mathrm{CdF}_{2}$ represents a deep trap for the electron. We have studied the insulating crystals by means of irradiation damage (thermoluminescence and EPR) and fluorescence; the semiconducting crystal has been studied in terms of optical absorption and EPR. The fluorescence spectrum of $\mathrm{Eu}^{3+}$ shows two kinds of local negative charge compensation which result in two different crystal field splittings. The thermoluminescence data are able to separate these two kinds of $\mathrm{Eu}^{3+}$ sites. The converted sample exhibits two absorption bands in the near-infrared region, one is peaked at $2650 \mathrm{~cm}^{-1}(0.33 \mathrm{eV})$ and the second at $1100 \mathrm{~cm}^{-1}(0.136 \mathrm{eV})$. The EPR measurements show that the electron is indeed trapped at the europium ion which results in a "normal" EPR spectrum of $\mathrm{Eu}^{2+}$. In addition, a broad signal is present at a certain angle $e^{5}$ which indicates the existence of exchange interaction between the conducting electron and the paramagnetic $\mathbf{E u}^{2+}$. This effect disappears at $77^{\circ} \mathrm{K}$ or lower temperature. On the basis of these experimental results we propose a model to explain the semiconducting properties of $\mathrm{CdF}_{2}: \mathrm{Eu}$.

\section{EXPERIMENTAL RESULTS}

\section{A. Irradiation Damage and Fluorescence of Insulating $\mathrm{CdF}_{2}: \mathbf{E u}$}

Unlike $\mathrm{CaF}_{2}, \mathrm{SrF}_{2}$, and $\mathrm{BaF}_{2}$, where the europium ion is embedded in the host mainly as $\mathrm{Eu}^{2+}$, in insulating $\mathrm{CdF}_{2}$, only the trivalent state is found in our crystals. The EPR spectrum of our samples at room temperature and liquid nitrogen temperature shows only a small amount of $\mathrm{Mn}^{2+}$ [see Fig. 1(a)]. X-ray irradiation of the $\mathrm{CdF}_{2}: \mathrm{Eu}$ results in partial conversion of $\mathrm{Eu}^{3+}$ to $\mathrm{Eu}^{2+}$ and a trapped hole in the lattice [see Fig. 1(b)]. Angular variation of the spectrum of a crystal oriented in (100) plane shows that the local symmetry is cubic or very close to cubic. The $g$ factor $(g=1.988)$ and crystal field parameters are identical to those reported by Glaser and Glist. ${ }^{7}$ The nature of the hole which accompanies the $\mathrm{Eu}^{2+}$ ion has not been established. It is possible that $V_{K}{ }^{8}$ centers similar to the $V_{K}$ centers in $\mathrm{CaF}_{2}, \mathrm{SrF}_{2}$, and $\mathrm{BaF}_{2}$ exist. $^{9}$ Since the $g$ factor of these hole centers is also close to 2 , but their intensity is much weaker than the intensity of the paramagnetic divalent europium, it is not possible to confirm this assumption. The total angular momentum of $\frac{7}{2}$ for $\mathrm{Eu}^{2+}$ and $\frac{1}{2}$ for the $V_{K}$ centers is the reason for the difference in the intensity since the spin magnetization is proportional to $S(S+1)$.

Heating the irradiated sample from $77^{\circ} \mathrm{K}$ up to $270^{\circ} \mathrm{K}$ results in gradual disappearance of the EPR spectrum of $\mathrm{Eu}^{2+}$ according to Fig. 2(b). A recombination process $\mathrm{Eu}^{2+}+$ hole $\rightarrow \mathrm{Eu}^{3+}$ occurs which is accompanied with thermoluminescence glow peak at $170^{\circ} \mathrm{K}$ [Fig. 2(a)]. Such a recombination process, 

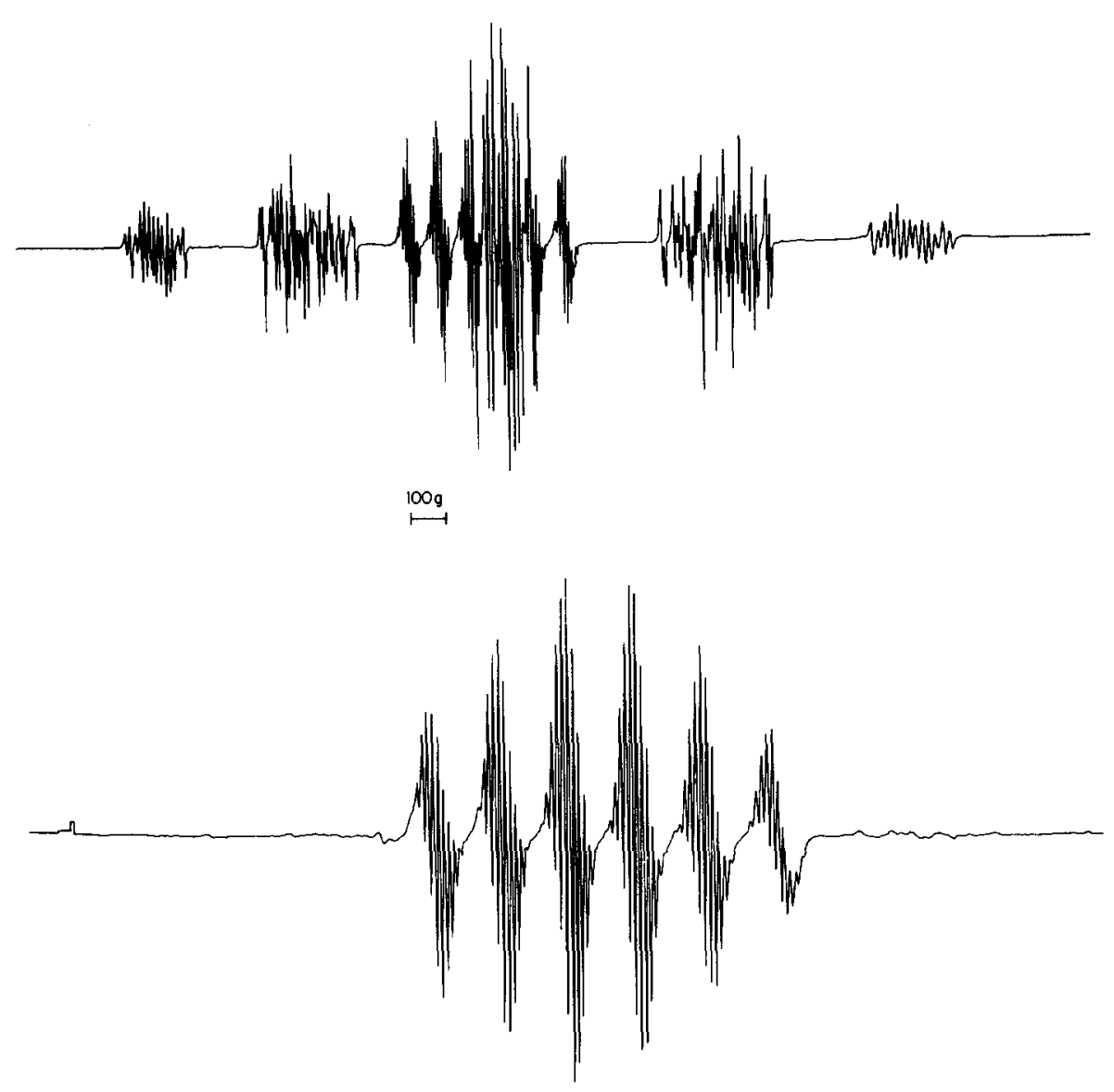

FIG. 1. (a) EPR spectrum around $g=2$ of the irradiated $\mathrm{CdF}_{2}: \mathrm{Eu}(0.02 \%)$. The magnetic field is oriented along the $\langle 100\rangle$ direction. The seven lines of $\mathbf{E u}^{++}$are superposed to the natural impurity of $\mathbf{M n}^{++}$in the crystal. (b) Nonirradiated crystal: only $\mathbf{M n}^{++}$ signal is present.

previously described in detail for $\mathrm{CaF}_{2}$ host ${ }^{10}$ doped with various rare earths, is particularly useful since the spectroscopy of the $\mathrm{Eu}^{3+}$ ion is revealed. In Figs. 3-5 the high resolution spectrum reveals that the europium ion is in symmetry sites lower than axial. The spectroscopy of the $\mathrm{Eu}^{3+}$ ion in various crystal field environments is well known. ${ }^{11-13}$ The thermoluminescence of $\mathrm{Eu}^{3+}$ below $170^{\circ} \mathrm{K}$ is very different from the thermoluminescence above $170^{\circ} \mathrm{K}$ (see Figs. 3,4 and Table $\mathrm{I}$ ). It is easy to identify these thermoluminescence spectra with the ${ }^{5} D_{0}$ to ${ }^{7} F_{1}$ transition (see Refs. 5-7). Since ${ }^{5} D_{0}$ is a single level and cannot

TABLE I. Thermoluminescence data on $\mathrm{CdF}_{2}: \mathrm{Eu}$ ( ${ }^{5} D_{0}$ to ${ }^{7} F_{1}$ transition).

\begin{tabular}{ccccc}
\hline \multicolumn{2}{c}{ Data below $170^{\circ} \mathrm{K}$} & & \multicolumn{2}{c}{ Data above $170^{\circ} \mathrm{K}$} \\
\cline { 4 - 5 }$(\AA)$ & $\left(\mathrm{cm}^{-1}\right)$ & & $(\AA)$ & $\left(\mathrm{cm}^{-1}\right)$ \\
\hline 5936 & 16846 & 5930 & 16863 \\
5921 & 16889 & 5905 & 16934 \\
5906.5 & 16930 & 5890 & 16977 \\
\hline
\end{tabular}

be split, the group of three lines belongs to the splitting of ${ }^{7} F_{1}$ in the crystal field. The Hamiltonian of this level with spin $S=1$ is given by:

$\mathfrak{H}=A /\left\{4 S(S-1)\left[3 S_{Z}{ }^{2}-S(S+1)+\frac{1}{2} \eta\left(S_{+}{ }^{2}+S_{-}{ }^{2}\right)\right]\right\}$

or

$\mathfrak{F}=A /\left\{4\left[3 S_{Z}{ }^{2}+\frac{1}{2} \eta\left(S_{+}{ }^{2}+S_{-}{ }^{2}\right)\right]\right\}, \quad$ for $S=1$.

The constants $A$ and $\eta$ describe the crystal field splitting. Formally the Hamiltonian has the same form as the one conventionally used to describe the pure nuclear quadrupole interaction, ${ }^{14} \eta$ describes the discrepancy from axial symmetry. For $\eta=0$ there are two degenerate energy levels corresponding to the states $| \pm 1\rangle$ and single state $|0\rangle$. This is the case of axial symmetry. For $\eta \neq 0$ the three levels are split. The coefficient $\eta$ changes from 0 to 1 in the Hamiltonian (1), where the $z$ direction is defined as the direction of the largest component of the second derivative of the electric potential which interacts with the quadrupole moment of the electronic wavefunction of 

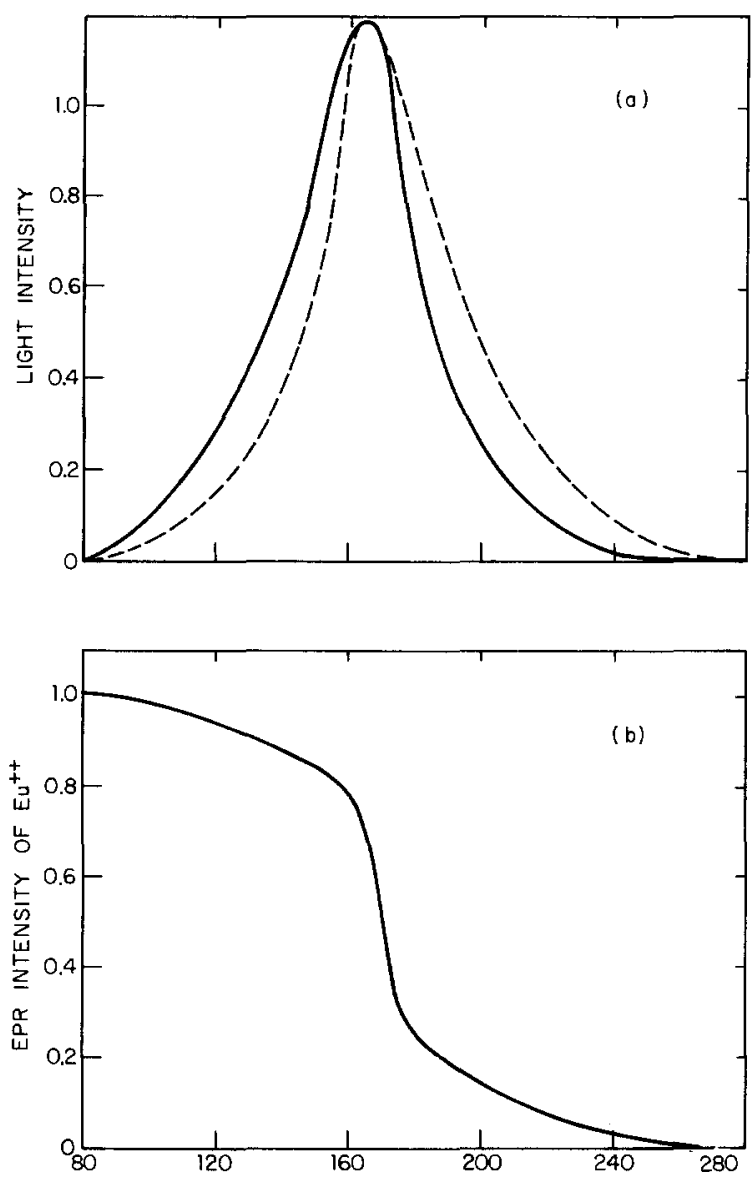

FIG. 2. (a) The solid line represents the total intensity of the thermoluminescence as a function of the temperature for $\mathrm{CdF}_{2}: \mathrm{Eu}(0.02 \%)$; the dotted line represents the thermoluminescence of $\mathrm{CdF}_{2}: \mathrm{Eu}(0.07 \%)$ as a function of the temperature. (b) The EPR intensity of $\mathrm{x}$-irradiated $\mathrm{CdF}_{2}: \mathrm{Eu}(0.02 \%)$ is plotted vs temperature.

$\mathrm{Eu}^{3+}$ in the ${ }^{7} F_{1}$ group of levels:

$$
\begin{gathered}
E_{1.2}=\frac{3}{4 A(1 \pm \eta / 3)}, \\
A=\frac{2}{3\left(E_{1}+E_{2}\right)} ; \quad \eta=3 \frac{E_{1}-E_{2}}{E_{1}+E_{2}},
\end{gathered}
$$

where $E_{1}$ and $E_{2}$ are the energy gaps according to Fig. 6.

The fluorescence data shown in Fig. 5 of $\mathrm{CaF}_{2}: \mathrm{Eu}$ are different from Kingsley and Prener $^{13}$ (see Table XIII). They reported data in which it is clear that the symmetry of the $\mathrm{Eu}^{3+}$ ion is very close to axial symmetry. The reason for the discrepancy is probably that the charge compensation, which depends on the crystal growing conditions, is quite different. We are able to detect neatly the following groups of lines: ${ }^{5} D_{0}-7 F_{1},{ }^{5} D_{0}-7 F_{2},{ }^{5} D_{0}-7 F_{3}$, and ${ }^{5} D_{0}-^{7} F_{4}$ (see Figs. 6 and 7). The results are tabulated in Table II and shown in Fig. 7. The two spectra of thermoluminescence can be seen in the fluorescence spectrum [Fig. 6(b)].
The advantages of thermoluminescence in spectroscopy of ions in the crystal field are obvious. For comparison we also examine the fluorescence spectrum of double doped $\mathrm{CdF}_{2}$ (with $\mathrm{Eu}$ and $\mathrm{Na}$ ) : see Table II. In this case we obtained only the ${ }^{5} D_{0^{-}}{ }^{7} F_{1}$ transition which was very intense. This spectrum also consists of three lines and indicates symmetry sites lower than axial. The parameters of $A$ and $\eta$ [see Eq. (3)] are:

(a) Low-temperature thermoluminescence $A=83.3$ $\mathrm{cm}^{-1} ; \eta=0.792$.

(b) High-temperature thermoluminescence $A=$ $-104.7 \mathrm{~cm}^{-1} ; \eta=0.678$.

(c) Double doped $\mathrm{CdF}_{2}$ fluorescence $A=-36.7$ $\mathrm{cm}^{-1} ; \eta=0.678$.

\section{B. Optical Absorption and EPR of Semiconducting $\mathrm{CdF}_{2}: \mathrm{Eu}$}

If $\mathrm{CdF}_{2}: \mathrm{Eu}$ is baked in $\mathrm{Cd}$ vapor the insulating $\mathrm{CdF}_{2}\left(\zeta \sim 10^{9} \Omega \cdot \mathrm{cm}\right)$ is converted to a semiconductor $(\zeta \sim 500 \Omega \cdot \mathrm{cm})$. Since $\mathrm{Eu}^{3+}$ is a much deeper trap than the shallow traps such as $\mathrm{Cd}, \mathrm{Sm}, \mathrm{Y}, \mathrm{Yb}$, the resistivity is two or three orders of magnitude larger for this semiconductor. Figure 8 shows the nearinfrared absorption spectrum of converted $\mathrm{CdF}_{2}: \mathrm{Eu}$. Two broad absorption peaks are found peaked at $2650 \mathrm{~cm}^{-1}(0.33 \mathrm{eV})$ and $1100 \mathrm{~cm}^{-1}(0.136 \mathrm{eV})$. These peaks do not exist in the unconverted sample. The absorption in the visible region reveals the

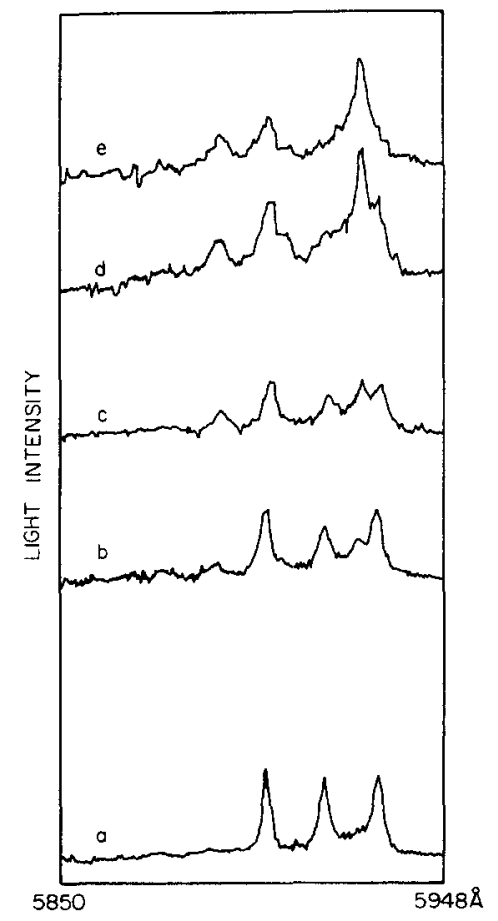

FIG. 3. Thermoluminescence spectra of $\mathrm{CdF}_{2}: \mathrm{Eu}(0.02 \%)$ as a function of the temperature; trace a as the lowest temperature range; $b, c$, and $d$ are spectra at intermediate temperatures; $\mathrm{e}$ the highest temperature range. 
FIG. 4. (a) Thermoluminescence spectrum of $\mathrm{CdF}_{2}: \mathrm{Eu}$ $(0.07 \%)$ below $170^{\circ} \mathrm{K}$; these lines are assigned to the ${ }^{5} D_{0^{-}}$ ${ }^{7} F_{1}$ transition. (b) Same as (a) above $170^{\circ} \mathrm{K}$.
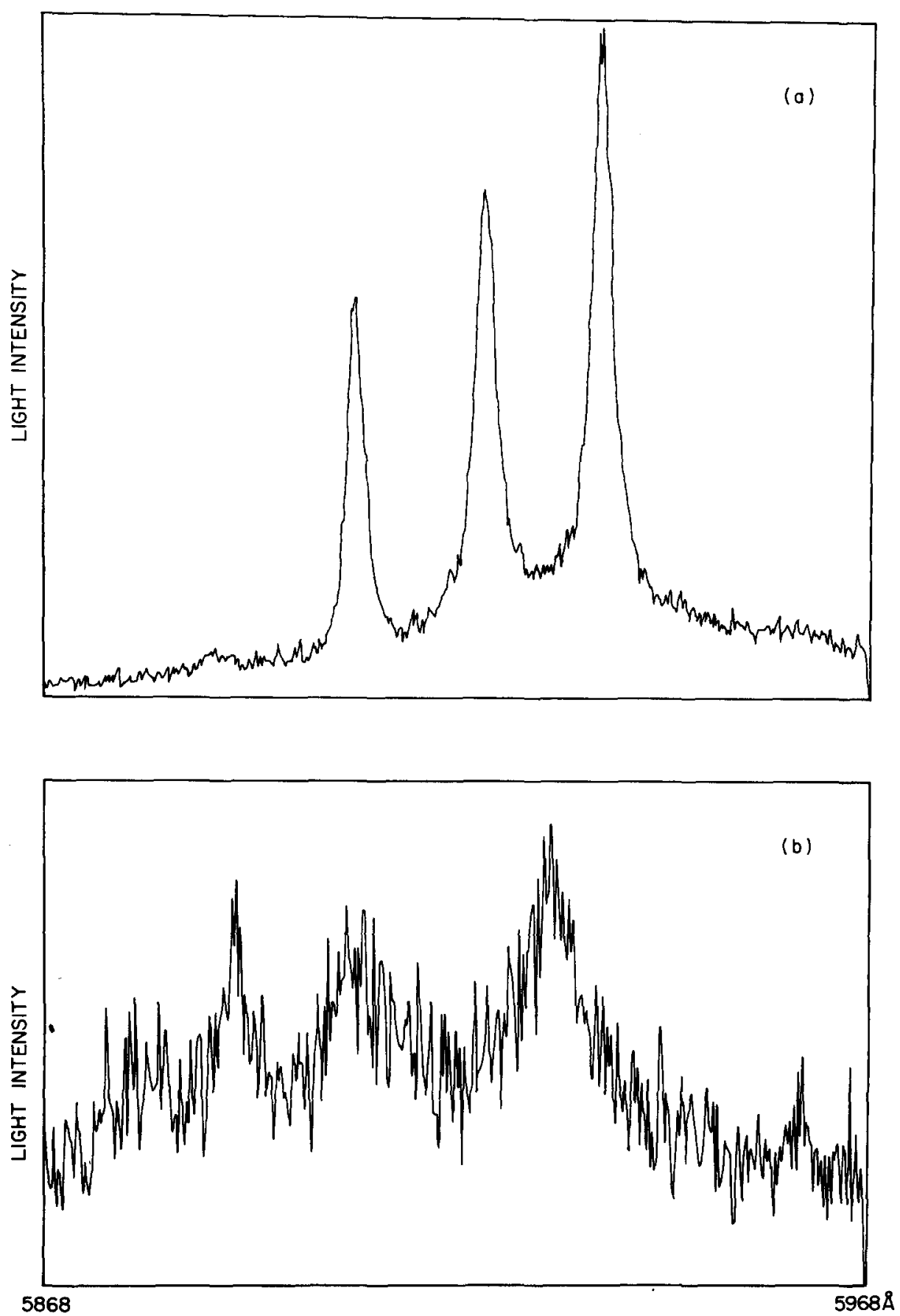

existence of $\mathrm{Eu}^{2+}$. The 337-m $\mu$ peak is identical with previously reported results. ${ }^{6}$

The converted $\mathrm{CdF}_{2}: \mathrm{Eu}$ is studied by EPR technique. The spectrum at $77^{\circ} \mathrm{K}$ confirms the existence of $\mathrm{Eu}^{2+}$. The $g$ factor, the crystal field parameters and the hyperfine structure are identical to those of the $\mathrm{x}$-irradiated sample. We studied the EPR spectrum at room temperature, 77 , and $4.2^{\circ} \mathrm{K}$. The intensity of $\mathrm{Eu}^{2+}$ spectrum at $77^{\circ} \mathrm{K}$ is 4.5 times greater than the spectrum at room temperature. In both cases the intensity of the spectrum of $\mathrm{Eu}^{2+}$ is compared to the intensity of $\mathrm{Mn}^{2+}$ at low power to avoid saturation effects. At room temperature in addition to the normal $\mathrm{Eu}^{2+}$ spectrum a broad line is observed. This broad line is observed only when the magnetic field is at a certain angle, so that the seven Zeeman split energy gaps of the ${ }^{8} S_{7 / 2}$ ground state are approximately equal. ${ }^{15}$ As in the case of $\mathrm{Gd}^{3+}$ in $\mathrm{CdF}_{2}$, when converted, this eight resonance is interpreted as an average line due to the exchange interaction between the con- 

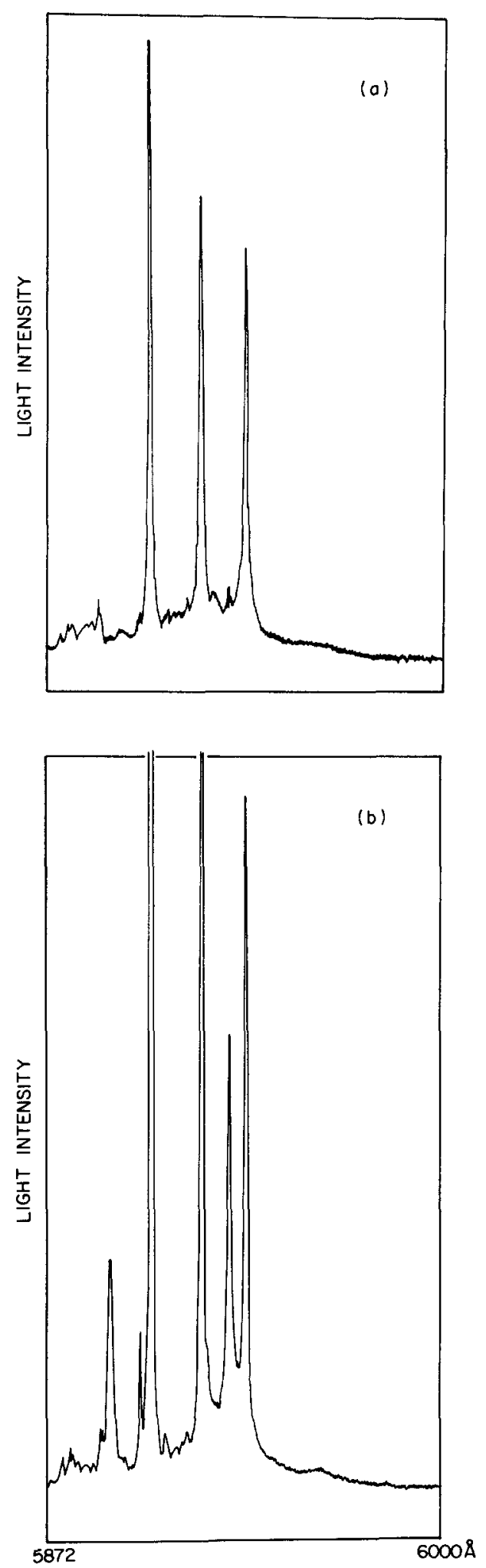

FIG. 5. (a) Fluorescence spectrum of $\mathrm{CdF}_{2}: \mathrm{Eu}(0.07 \%)$. The three intense lines are assigned to the ${ }^{5} D_{0}-7 F_{1}$ transition $\left(77^{\circ} \mathrm{K}\right)$. (b) Fluorescence spectrum of $\mathrm{CdF}_{2}: \mathrm{Eu}(0.02 \%)$; the superposition of the two kinds of spectra is shown $\left(\left(77^{\circ} \mathrm{K}\right)\right.$. duction electron and $\mathrm{Eu}^{2+}$. This broad signal disappears when the sample is cooled down to $77^{\circ} \mathrm{K}$ and the intensity of $\mathrm{Eu}^{2+}$ is increased. No difference is observed between the $\mathrm{Eu}^{2+}$ spectrum at 4.2 and $77^{\circ} \mathrm{K}$.

The width of the "eighth resonance" line at room temperature close to the "magic angle" (when the energy levels are equally spaced) is changing according to the following table:

$$
\begin{array}{lrrrrr}
\theta\left(^{\circ}\right) & 0 & 2 & 3 & 4 & 6 \\
\Delta f(\mathrm{~g}) & 120 & 200 & 240 & 320 & 550 .
\end{array}
$$

\begin{tabular}{|c|c|c|c|}
\hline$(\AA)$ & $\left(\mathrm{cm}^{-1}\right)$ & $(\AA)$ & $\left(\mathrm{cm}^{-1}\right)$ \\
\hline \multicolumn{4}{|c|}{ (1) ${ }^{5} D_{0}$ to ${ }^{7} F_{1}$ transition } \\
\hline 5936 & 16846 & 5931 & 16860 \\
\hline 5921 & 16889 & 5903 & 16940 \\
\hline 5906 & 16931 & 5891 & 16975 \\
\hline \multicolumn{4}{|c|}{ (2) ${ }^{5} D_{0}$ to ${ }^{7} F_{2}$ transition } \\
\hline 6185 & 16168 & & \\
\hline 6176 & 16192 & & \\
\hline 6163 & 16226 & & \\
\hline 6148 & 16265 & & \\
\hline 6145 & 16273 & & \\
\hline \multicolumn{4}{|c|}{ (3) ${ }^{5} D_{0}$ to ${ }^{7} F_{3}$ transition } \\
\hline 6520 & 15337 & & \\
\hline 6518 & 15342 & & \\
\hline 6515 & 15349 & & \\
\hline 6459 & 15397 & & \\
\hline 6492 & 15404 & & \\
\hline 6486 & 15418 & & \\
\hline 6471 & 15454 & & \\
\hline \multicolumn{4}{|c|}{ (4) ${ }^{5} D_{0}$ to ${ }^{7} F_{4}$ transition } \\
\hline 6927 & 144.36 & & \\
\hline 6915 & 14461 & & \\
\hline 6907 & 14478 & & \\
\hline 6905.5 & 14481 & & \\
\hline 6895 & 14503 & rlappin & \\
\hline 6843 & 14613 & & \\
\hline 6825 & 14652 & & \\
\hline 6816 & 14671 & & \\
\hline \multicolumn{4}{|c|}{ Fluorescence data of $\mathrm{CdF}_{2}: \mathrm{Eu}: \mathrm{Na}$ at $77^{\circ} \mathrm{K}$} \\
\hline \multicolumn{4}{|c|}{ (1) ${ }^{5} D_{0}$ to ${ }^{7} F_{1}$ transition } \\
\hline$(\AA)$ & $\left(\mathrm{cm}^{-1}\right)$ & & \\
\hline 5907 & 16929 & & \\
\hline 5904 & 16938 & & \\
\hline 5896 & 16961 & & \\
\hline
\end{tabular}

TABLE II. Fluorescence data of $\mathrm{CdF}_{2}: \mathrm{Eu}$ at $77^{\circ} \mathrm{K}$. 
The crystal is rotated in the (100) plane relative to the magnetic field.

It is difficult in the case of europium to estimate the exchange interaction because of the anisotropic hyperfine interaction with the two nuclear isotopes $\left({ }^{151} \mathrm{Eu}\right.$ and $\left.{ }^{153} \mathrm{Eu}\right)$.

\section{EXPERIMENTAL TECHNIQUE}

The $\mathrm{CdF}_{2}$ single crystals used in this work were grown in graphite crucibles by use of BrodgenerStockbarger technique. ${ }^{16-19}$ The $\mathrm{CdF}_{2}$ powder was obtained from the General Electric Chemical Products Plant. The pure powder was first purified by repeated growth of single crystals. After each growth the top end was cut off and the remainder was ground up to be used as initial powder for the next growth. After purification the dopant was added to the pure powder and thus regrown. As grown, the samples were highly insulating. A Pyrex tube was cleaned and baked under vacuum at $500^{\circ} \mathrm{C}$ for $2 \mathrm{~h}$. The doped sample and a piece of cadmium metal were placed in the tube so

FIG. 6. Scheme of the crystal field split of ${ }^{7} F_{1}$ level.

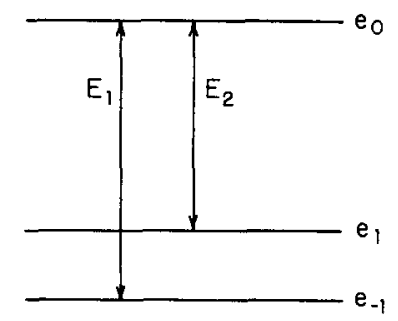

that they were physically separated. The tube was sealed and placed in a furnace. The crystal was heated at about $600^{\circ} \mathrm{C}$ for half an hour and removed from the furnace while hot.

Electron spin resonance data were taken with Varian V-4500 35-Gc/sec spectrometer. A special attachment has been built ${ }^{2}$ to allow both $x$-ray irradiation and collection of EPR data, keeping the sample at $77^{\circ} \mathrm{K}$. Figure 9 shows the attachment which consists of a quartz Dewar with two suprasil quartz windows, 0.020 in. thick each. $\mathrm{X}$-ray exposures are made with a molybden $x$-ray tube powered by a General Electric supply operated at $50 \mathrm{kV}$ and $20 \mathrm{~mA}$. The bottom part of the $35-\mathrm{Gc} / \mathrm{sec}$ cavity and the cold finger are supported by springs. The sample is at the level of the window during x-ray exposure. After the irradiation, the cavity and the wave guide with the iris is screwed up into the bottom part of the cavity. They are pushed down so the sample sits on the middle of the 8-in. pole of the Harvey-Wells Nuclear Corp. magnet. The sample temperature is measured by a copper-constantant thermocouple (made from 30gauge wire) with reference junction in icewater. The thermocouple junction is pressed to the bottom part
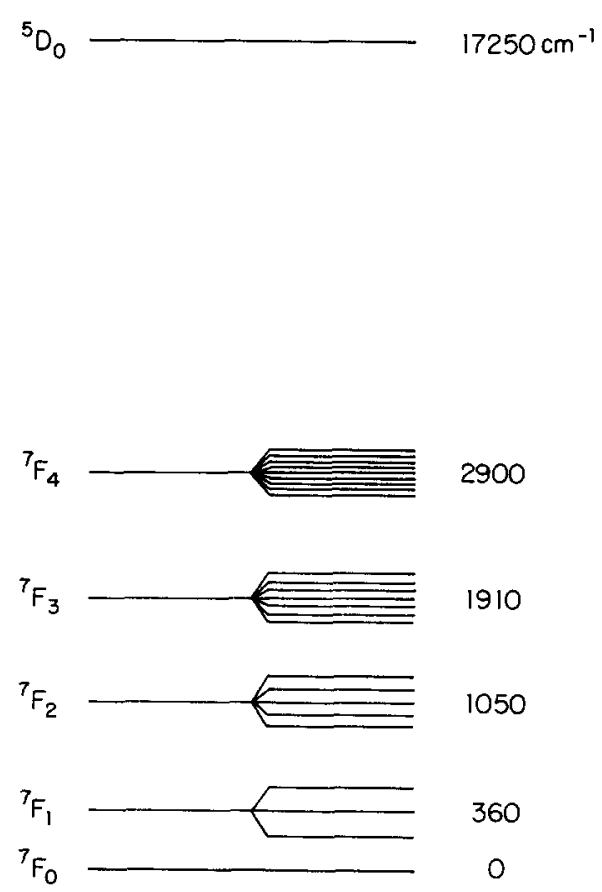

FIG. 7. Scheme of the electronic energy levels of $\mathrm{Eu}^{3+}$.

of the cavity, as close to the sample as possible. The static magnetic field is measured by a free precession NMR signal with spin-echo apparatus.

The absorption measurements in the visible region are done in a Cary 14 spectrometer and the nearinfrared region in a Cary-White 90 spectrometer. A liquid nitrogen Dewar with $\mathrm{KBr}$ windows is used for this purpose.

The high-resolution spectrum of thermoluminescence as well as the fluorescence spectrum is taken with Jarrel-Ash 1-m spectrometer (model 78-420). The excitation of the fluorescence spectrum is done by uv mercury lamp (General Electric Co., Hendersonville, N. C.), model B-H6 (900 W).

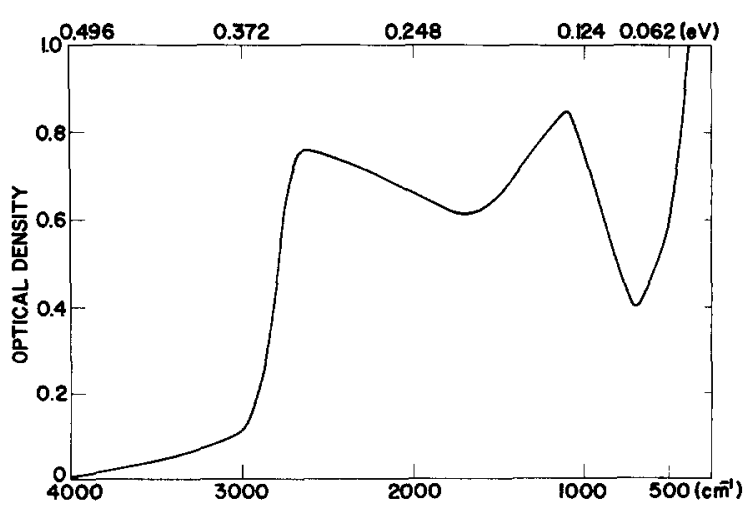

FIG. 8. Near-infrared absorption of semiconducting $\mathrm{CdF}_{2}: \mathrm{Eu}(0.07 \%)$. 


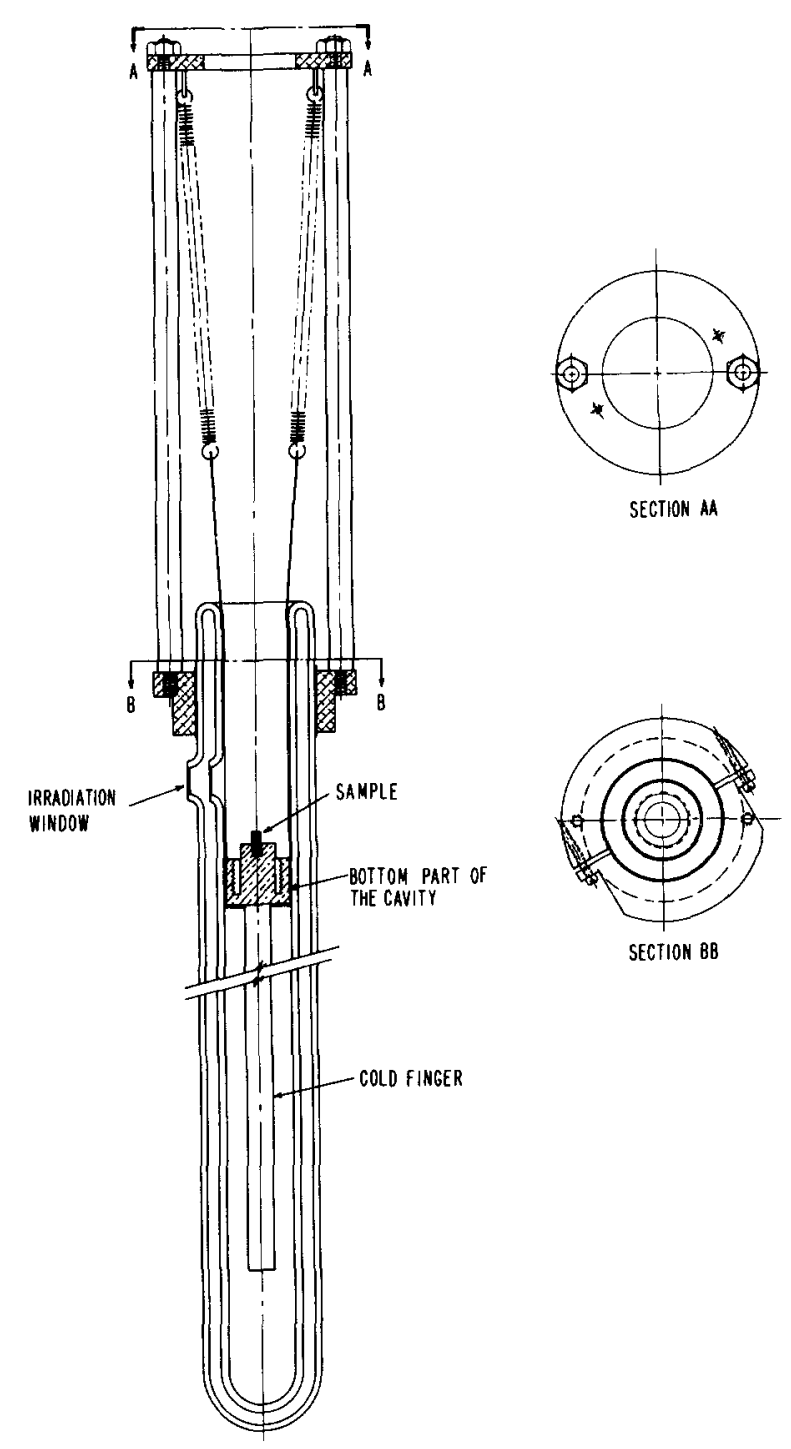

Frg. 9. Liquid nitrogen quartz Dewar with the bottom part of the cavity supported by springs. This attachment allows us to irradiate the sample at $77^{\circ} \mathrm{K}$ and measure the EPR spectra without heating the sample. The Dewar is used also to measure the thermoluminescence spectra.

The dimensions of the sample used in the fluorescence and thermoluminescence are: $10 \times 10 \times 6 \mathrm{~mm}$; for EPR experiments $-6 \times 1.6 \times 1.6 \mathrm{~mm}$; the thickness of the sample used in optical absorption was about $1 \mathrm{~mm}$.

\section{DISCUSSION}

Irradiation damage ( $\mathrm{x}$-ray irradiation at $77^{\circ} \mathrm{K}$ ) is almost not manifested in pure $\mathrm{CdF}_{2}$ or $\mathrm{CdF}_{2}$ doped with "shallow traps" rare earth. When Eu ions are not present the thermoluminescence intensity is about three orders of magnitude less and is probably not connected with the specific rare earth. The thermoluminescence of $\mathrm{Eu}^{3+}$ in $\mathrm{CdF}_{2}$ is quite strong and it has the feature that is identical to the luminescence spectrum excited by uv source. This proves the assumption that $\mathrm{Eu}^{3+}$ is a deep electron trap in the $\mathrm{CdF}_{2}$ host. The shallow electron traps (rare earth) repel the electron mainly on the $5 s$ shell of the cadmium. The EPR of $\mathrm{Eu}^{2+}$ due to the $x$-ray irradiation at $77^{\circ} \mathrm{K}$ (Fig. 1) in cubic or almost cubic sites proves that the electron excited from the valence fluorine band is excited into the cadmium conduction band, which lies at least $6 \mathrm{eV}$ higher than the valence band, and trapped into the $\mathrm{Eu}^{3+}$, thus converting it into $\mathrm{Eu}^{2+}$. As shown in Fig. 2, the electron (or the hole center) is mobile and thermally activated at $170^{\circ} \mathrm{K}$. As a result a recombination occurs ${ }^{9,10}$ and one is able to observe the spectroscopy of $\mathrm{Eu}^{3+}$. The experimental results show that there are two kinds of low symmetry sites for $\mathrm{Eu}^{3+}$. It is logical to assume that interstitial fluorines or cadmium vacancies cause this low symmetry; Interstitial fluorine in $\langle 210\rangle$ position from the europium ( $C_{1 h}$ symmetry) will split the three levels of ${ }^{7} F_{1}$.

It is clear from Figs. 3, 4, and 7 that if the sample is more doped, the intensity of one kind of spectrum is increased relative to the intensity of the second kind. This suggests that this second kind of spectrum is related to a constant amount of some defect $\left(\mathrm{Cd}^{2+}\right.$ vacancy, for instance), which does not depend on the amount of doping. It is striking that the $\mathrm{Eu}^{2+}$ is in cubic symmetry but the thermoluminescence spectrum is a low symmetry one. A possible explanation is that the level ${ }^{8} S_{7 / 2}$ belongs to an $S$-site ion where the crystal field splitting affects it only in higher orders, whereas the amount of splitting for the ${ }^{7} F_{1}$ is much greater (of the order of $100 \mathrm{~cm}^{-1}$ ). We wish to compare this result with the zero field splitting of $\mathrm{Gd}^{3+}$ in $\mathrm{CaF}_{2}$ in the ground $\left({ }^{8} S_{7 / 2}\right)$ and an excited state $\left({ }^{6} P_{7 / 2}\right)$. From the cubic EPR spectrum the zero field splitting is $0.149 \mathrm{~cm}^{-1}$; however, the splitting of ${ }^{6} P_{7 / 2}$ level from fluorescence measurement of Mokovsky ${ }^{20}$ is $56.6 \mathrm{~cm}^{-1}$.

On the basis of optical absorption and EPR data, we wish to propose the following model for the semiconducting $\mathrm{CdF}_{2}: \mathrm{Eu}$; this model is consistent with the experimental results obtained for the insulating $\mathrm{CdF}_{2}: \mathrm{Eu}$. The ground state of the conduction electron is the $\mathrm{Eu}^{2+}$, which merely means that the low-lying energy level represents the europium impurity site (trap). The first excited state which is $0.136 \mathrm{eV}$ above the ground state is 12 times degenerate; it represents the 12 cadmium nearest-neighbor sites at $\langle 110\rangle$ type of direction from the europium impurity. At $77^{\circ} \mathrm{K}$ the ground state $\left(\mathrm{Eu}^{2+}\right)$ is four times more populated (Boltzmann factor) than at room temperature. This property is exhibited in the increase of the intensity of EPR of the $\mathrm{Eu}^{2+}$ at $77^{\circ} \mathrm{K}$ relative to the intensity at room temperature. The increase in intensity is relative to the $\mathrm{Mn}^{2+}$ signal. The conduction band consists of more distant cadmium sites relative to the rare earth in $0.33 \mathrm{eV}$ above the ground state. 
* This work was supported in part by the Joint Services Electronics Program (U.S. Army, U.S. Navy, and U.S. Air Force) under Contract No. N00014-67-A-0298-0006 and by the Division of Engineering and Applied Physics, Harvard University.

t Present address: Microwave Division, The Racah Institute of Physics, The Hebrew University of Jerusalem, Israel.

1 J. D. Kingsley and J. S. Prener, Phys. Rev. Letters 8, 315 (1962).

2 Z. J. Kiss and P. N. Yocom, J. Chem. Phys. 41, 1511 (1964).

3 P. F. Weller, Inorg. Chem. 4, 1545, (1965).

${ }^{4}$ W. M. Latimer, Oxidation Potentials (Prentice-Hall, Englewood Cliffs, N.J., 1938), pp. 293-301.

${ }^{5}$ P. Eisenberger and P. S. Pershan, Phys. Rev. 167, 292 (1968).

${ }_{6}^{6}$ F. Trautweiler, F. Moser, R. P. Khosla, J. Phys. Chem. Solids 29, 1869 (1968).

7 H. J. Glazer and D. Geist, Z. Naturforsch. 20a, 842 (1965).

8 W. Hayes and J. W. Twidell, Proc. Phys. Soc. (London) 29, 1295 (1962) ; Paramagnetic Resonance, edited by W. Low (Academic, New York, 1963), Vol. 1., p. 163.

${ }^{9}$ A. Tzalmona and P. S. Pershan, Appl. Phys. Letters 13, 262

(1968) ; Phys. Rev. 182, 906, (1969).

${ }^{10}$ J. L. Mertz and P. S. Pershan, Phys. Rev. 162, 217, 235
(1967); Optical Properties of Ions in Crystals, edited by H. M. Crosswhite and H. W. Moos (Interscience, New York, 1967), p. 117 ; J. L. Mertz, Ph.D. thesis, submitted to Harvard University, December, 1966.

${ }^{11}$ N. C. Chang and J. B. Gruber, J. Chem. Phys. 41, 3227, (1964).

${ }_{12} \mathrm{O}$. J. Sovers and T. Yoshioka, J. Chem. Phys. 49, 4945 (1968).

${ }^{13}$ J. D. Kingsley and J. S. Prener, Phys. Rev. 126, 458 (1962).

${ }_{14}$ T. P. Das and E. L. Kahn, Nuclear Quadrupole Resonance

Speciroscopy (Academic, New York, 1958), Chap. 1.

${ }_{15}$ W. Low, Phys. Rev. 105, 265 (1958).

${ }_{16}$ D. C. Stockberger, J. Opt. Soc. Am. 39, 731 (1949).

${ }^{17}$ I. V. Stepanov and P. P. Folfilov in Growth of Crystals, edited by A. V. Shubnikov and N. N. Sheftal (Consultants Bureau, New York, 1959), Vol. 1. Chap. IV.

${ }^{18}$ H. M. Baker, W. Hayes, and D. A. Jones, Proc. Phys. Soc. (London) 73, 942, (1959).

${ }^{19} \mathrm{H}$. Guggenheim, J. Appl. Phys. 34, 2482, (1963).

${ }^{20} \mathrm{~J}$. Makovsky, Phys. Quantum Electronics Conference, edited by P. L. Kelley, B. Lax, and P. E. Tannenwald (McGraw-Hill, New York, 1966); J. Chem. Phys. 46, 390 (1967).

\title{
Kinetic Salt Effects on the Aquation Reaction of the Azidopentaaquochromium (III) Ion and Predictions of the Mayer Theory
}

\author{
A. Indelli and R. De Santis \\ Istituto di Chimica Analitica ed Elettrochimica, Via Risorgimento, 35-Pisa, Italy
}

(Received 2 June 1971)

\begin{abstract}
The rate of the reaction of aquation of the azidopentaaquochromium(III) ion has been measured at two different concentrations of hydrogen ion in the presence of a number of salts. The values of $k_{1}$ and $k_{0}$ of the equation

$$
k_{\mathrm{ob} B}=k_{1}\left[\mathrm{H}^{+}\right]+k_{0}+k_{-1}\left[\mathrm{H}^{+}\right]^{-1}+k_{-2}\left[\mathrm{H}^{+}\right]^{-2}
$$

were calculated and both show positive salt effects and obey the Olson-Simonson rule. Calculations performed using the Mayer theory in the approximation "DHLL $+\mathrm{B}_{2}$ " have shown that at high dilution both these effects can be rationalized using appropriate values of the distances of closest approach. The possibility of using this form of the Mayer theory for extrapolation purposes is suggested. The use of different distances of closest approach for different pairs of ions does not lead to any inconsistency.
\end{abstract}

Kinetic salt effects on reactions involving ions of the same sign cannot, in general, be satisfactorily interpreted on the basis of the simple Bronsted-Debye theory. ${ }^{1}$ For reactions between anions the rate does not depend upon the ionic strength, $I$, but upon the nature and concentration of the cations, whereas for reactions between cations it is the concentration of the anions which is important. ${ }^{2}$ This can not be rationalized in terms of the Bronsted-Debye theory, even with the assumption of the formation of reactive ion pairs. ${ }^{3}$ Moreover, salt effects are sometimes observed also for unimolecular reactions or for reactions between an ion and a neutral molecule ${ }^{4}$ and these cannot be interpreted on the basis of the simple Bronsted-Debye theory but require the assumption of a specific ionic interaction. ${ }^{5}$ Quantitative studies on this subject are rather scarce. ${ }^{6}$ Moreover, the instances of salt effects in reactions between cations which are found in the literature are usually complicated by the formation of complexes of the reactants with the added salts and are not suitable for a study in terms of an electrostatic theory. Therefore we considered it useful to measure the salt effects in the aquation of the azidopentaaquochromium ion which offers interesting opportunities. In fact this reaction has been studied by Swaddle and King ${ }^{7}$ who found that the rate in a wide range of $\mathrm{H}^{+}$concentration and at an ionic strength $I=1.0 M$, could be expressed by the equation

$$
\begin{aligned}
V=k_{1}[\mathrm{Cr}]\left[\mathrm{H}^{+}\right]+k_{0}[\mathrm{Cr}]+k_{-1}[\mathrm{Cr}] /\left[\mathrm{H}^{+}\right] \\
+k_{-2}[\mathrm{Cr}] /\left[\mathrm{H}^{+}\right]^{2},
\end{aligned}
$$

where $[\mathrm{Cr}]$ is the concentration of the complex. The first rate constant, $k_{1}$, corresponds to a reaction between two cations, whereas the second, $k_{0}$, corresponds to a unimolecular reaction, or, possibly, to a reaction between a cation and a neutral solvent molecule. Under suitable conditions it is possible to neglect the contributions of the third and fourth terms. The Mayer theory, ${ }^{8}$ even in a very crude form, appears to be able 